is claimed to have a low pregnancy rate. Because of the advantages of postpartum or postplacental insertion, the multiload $\mathrm{Cu} 375$ device merits further investigation.

On the basis of this study, postpartum insertion of the combined copper multiload intra-uterine device provides an acceptable alternative to hormonal contraception, and can be recommended as a routine method of contraception, particularly in patients who are unlikely to continue with other methods.
REFERENCES

1. Van Os, W., Thiery, M. and Van der Pas, H. (1976): Paper presented at the 1st Congress of the Asian Federation of Obstetrics and Gynaecology, Singapore, 27 - 30 April 1976.

2. Banharnsupawat, L. and Rosenfield, A. (1971): Obstet. and Gynec., 38, 276.

3. Rosenfield, A. and Castadot, R. (1974): Amer. J. Obstet Gynec.

4. Rashbaum, W. and Wallach, R. C. (1971): Ibid., 109, 1003.

5. Viel, B. and Lucero, S. (1970): Ibid., 106, 765.

6. Weinberg, G. and Bailin, C. (1973): Obstet. and Gynec., 41, 925:

7. Mantorella, , A and Esputo, J. M. (1975): Reprod. Med, 14, 178.

8. Thiery, M., Van der Pas, H., Van Os, W. et al. (1976): Unpublished data.

\title{
Clinical and Haematological Problems Associated with Severe Abruptio Placentae
}

\author{
H. J. ODENDAAL, \\ S. BRINK, \\ J. G. STEYTLER
}

\section{SUMMARY}

\begin{abstract}
A clinical study was done of 80 patients in whom abruptio placentae was severe enough to cause intra-uterine death of the fetus. Central venous pressure was measured whenever possible to ensure adequate fluid replacement. Although the minority of the patients were shocked when admitted, blood replacement averaged 5 units per patient. The caesarean section incidence was $21 \%$. Only 1 patient developed renal failure for which peritoneal dialysis was done. No maternal deaths occurred. Serial coagulation studies were done in 58 patients. Diffuse intravascular coagulation was present in the majority. After delivery of the fetus, however, tests became normal.
\end{abstract}

S. Afr. med. J., 54, 476 (1978).

Extensive retroplacental haemorrhage occurs in patients in whom the abruption is severe enough to cause intrauterine death of the fetus. The volume of the concealed haemorrhage may amount to at least $2 \frac{1}{2}$ litres and may

\footnotetext{
Departments of Obstetrics and Gynaecology and Haematology, University of Stellenbosch and Tygerberg Hospital, Parowvallei, CP

H. J. ODENDAAL, м.B. CH.B., F.C.O.G. (S.A.), M.MED. (o. \& G.), M.R.C.O.G., M.D.

S. BRINK, M.B. CH.B., F.C. PATH. (S.A.)

J. G. STEYTLER, B.SC., M.SC., M.B. CH.B., M.MED. (РATH.), M.D. Date received: 19 January 1978.
}

exceed 5 litres. ${ }^{1}$ A high percentage of patients also develop coagulation deficiency and severe postpartum haemorrhage. ${ }^{2}$ Undertransfusion of fluids could cause tubular necrosis. Careful resuscitation of these patients is therefore of vital importance. Abruptio placentae is the most common cause of intra-uterine death in patients admitted to Tygerberg Hospital. This study deals with some of the problems encountered in these patients.

\section{PATIENTS AND METHODS}

Eighty patients were studied and serial coagulation studies were done in 58 patients. Patients with abruptio placentae and intra-uterine death admitted to Tygerberg Hospital were transferred to the intensive care unit as soon as possible after admission. A brief history was taken, the general condition of the patient assessed and the diagnosis of intra-uterine death confirmed. Blood was taken for crossmatching and coagulation studies. Clotting time, haemoglobin and haematocrit examinations were immediately done. Patients received an intravenous infusion into an arm vein and a catheter to measure central venous pressure (CVP) was inserted into the external jugular vein. Where necessary small doses of morphine or pethidine were given intravenously. The patient was then examined vaginally to assess the condition of the cervix and to rupture the membranes. Catheters were then inserted into the uterus and bladder to measure the contractions and urinary output. 
Initial fluid therapy consisted of a physiological electrolyte solution, usually Plasmalyte B or Ringer's lactate. Ample intravenous fluid was administered to maintain a urinary output of at least $30 \mathrm{ml} / \mathrm{h}$. Care was taken, however, not to exceed a CVP of $10 \mathrm{~cm}$ of water. Vital signs and CVP were recorded every 15 minutes. Depending on the strength and frequency of contractions and progress of labour, oxytocin was given. One $\mathrm{mU} / \mathrm{min}$ was administered to begin with and the infusion rate was doubled every 15 minutes until sufficient contractions were obtained or until $32 \mathrm{mU} / \mathrm{min}$ was reached. Uterine contractions were monitored on a Hewlett-Packard model 8020A cardiotocograph. Care was always taken when calibrating the pressure tranducer at the beginning of the recording and when necessary during the first stage of labour. When a blocked catheter was suspected, it was flushed with sterile water. Depending on the initial haematocrit value and coagulation studies, infusion of fresh blood was commenced as soon as possible. When fresh blood was not immediately available, banked blood was administered. In cases of severe coagulation defects, when crossmatched blood was not yet available, fresh frozen plasma and/or concentrated platelets were used.

When labour failed to progress in spite of adequate uterine contractions or when the uterus could not be stimulated, a caesarean section was done. However, care was always taken to correct the coagulation deficiency before the operation. Immediately after delivery, $5 \mathrm{U}$ of oxytocin and $0,5 \mathrm{mg}$ of ergometrine were given intramuscularly. An infusion of 20-40 U of oxytocin in 1000 $\mathrm{ml}$ of an electrolyte solution was started immediately after the delivery to prevent atonia of the uterus. If delivery of the placenta did not occur soon, the Brandt-Andrews method was used. The placenta was then examined to confirm the diagnosis of abruptio placentae. Postpartum blood loss and retroplacental blood clots were carefully measured and the fetus and placenta were weighed.

\section{Laboratory Methods}

Standard techniques were used. Activated partial thromboplastin time $(\mathrm{PTT})^{3}$, prothrombin ratio (PR) $)^{4}$ prothrombin activity (PA), ${ }^{5}$ fibrinogen levels, ${ }^{6}$ latex agglutination method for fibrinogen degradation products (FDP) ${ }^{7}$ thrombin time $(\mathrm{TT})^{8}$ and ethanol gelation test ${ }^{9}$ were estimated. Full blood counts were done with the Coulter Model S and platelet counts with the Coulter Model F. Blood smears were stained with Wright's stain. Blood was taken every 2 - 4 hours for haematological and coagulation studies. Repeated venepunctures were avoided by connecting a three-way stopcock to the CVP catheter. The first $5 \mathrm{ml}$ of blood withdrawn was always discarded to prevent dilution with the fluid being administered. These tests were also done in 26 patients with uncomplicated pregnancies at 38 weeks' gestation to obtain the normal values for pregnancy in this laboratory.

\section{Clinical Results}

Gravidity ranged from 1 to 11 . Twenty-three patients were primigravidas and 15 had had more than 5 previous pregnancies. Ages ranged from 16 to 46 years with a mean of 27,1 years. Only 39 patients were booked. Of these patients, 7 had hypertension, 4 proteinuria, 1 pre-eclampsia and 1 a previous episode of antepartum haemorrhage. Weight gain during pregnancy could not be assessed in 4 patients because of infrequent antenatal visits. Weight gain was poor in 14 patients. Serological tests for syphilis were positive in 3 booked patients. Blood pressure on admission before any resuscitation had been done ranged from $40 / 0$ $\mathrm{mmHg}$ to $170 / 130 \mathrm{mmHg}$. The mean systolic blood pressure was $121 \pm 23 \mathrm{mmHg}$ and was lower than $100 \mathrm{mmHg}$ in only 8 patients. Mean diastolic blood pressure was $78 \pm$ $20 \mathrm{mmHg}$. Diastolic values of $90 \mathrm{mmHg}$ or more were seen in $27(34 \%)$ patients. CVP could be measured in 53 patients and initial values ranged from -2 to $12 \mathrm{~cm} \mathrm{H}_{2} \mathrm{O}$ with a mean of 4,9 . Packed cell volumes on admission ranged from $17 \%$ to $40 \%$ with a mean of $28 \pm 5 \%$. The amount of blood transfused ranged from 0 to 19 units per patient with a mean of 5,1 . Only 4 patients did not receive any blood. Fresh frozen plasma was given to 15 patients, concentrated platelets to 5 and fibrinogen to 2 .

Postpartum blood loss, including the retroplacental clots, ranged from 120 to $4500 \mathrm{ml}$ with a mean of $1052 \mathrm{ml}$. Retroplacental clot volume could be measured in 40 patients and ranged from 100 to $2000 \mathrm{ml}$ with a mean of $709 \mathrm{ml}$.

Duration of pregnancy was known in 46 patients and ranged from 17 to 40 completed weeks, the mean being 32 weeks. Birth weights ranged from 210 to $3340 \mathrm{~g}$ with a mean of $1831 \mathrm{~g}$. There was one twin pregnancy. The mean placental weight was $451 \mathrm{~g}$. Duration of the first stage of labour ranged from 30 minutes to 26 hours, the mean being 9,2 hours. Normal vertex deliveries occurred in 57 patients. There were 3 vacuum extractions, 3 breech deliveries and 1 transverse lie. Caesarean section was done in 17 patients, giving an incidence of $21 \%$. There were 42 male and 38 female infants.

\section{Complications}

Eleven patients developed complications during or after treatment. A patient who had been treated for pulmonary tuberculosis up to 6 months before delivery was admitted unbooked. Following the caesarean section, severe dyspnoea developed as well as a rise in temperature. She also developed pulmonary oedema and was ventilated for 5 days. The CVP was not measured in this patient. Recovery was uneventful. Rupture of the uterus occurred in 1 patient and a hysterectomy was subsequently performed. Pulmonary oedema necessitated assisted ventilation. The CVP was also not monitored in this patient. Postoperative anuria was seen in 1 patient delivered by caesarean section. Heparin was given postoperatively in rather excessive doses. The anuria cleared after conservative therapy. However, recovery was further hampered by a severe haematoma in the abdominal wound which had to be evacuated. She received 19 units of blood. Eventual recovery was complete.

Continuous postpartum bleeding occurred in 5 patients. In 3 the cause was an atonic uterus which later responded 
to oxytocin stimulation. In 1 patient, haemorrhage was due to an episiotomy not being sutured properly and in another it was due to a large cervical tear after a normal delivery. The coagulation deficiency could not have contributed to the haemorrhage as it had been corrected by this time. Suturing of the laceration was done under general anaesthesia.

In 1 of the patients, in whom the uterus remained atonic, the blood pressure was low for some time. Although urinary output was normal the blood urea gradually rose to $51 \mathrm{mmol} / \mathrm{l}$. A peritoneal dialysis was performed once. The blood urea level then started to decline slowly. The patient also had longstanding pre-existing hypertension and this probably also contributed to the renal failure. A small increase in blood urea was seen in another patient but it returned to normal spontaneously. Two patients developed fever during the puerperium. In one case it was due to a genital infection and in the other to pneumonia. Both patients responded well to treatment.

\section{Laboratory Results}

The pattern of abnormalities is continuously changing and the results are evaluated in relation to the clinical condition. The mean and standard deviation are given for each normal value.

Platelet count. Platelet counts were done in 51 patients on admission. The count exceeded $200000 / \mu 1$ in only 13 patients. Values below $100000 / \mu l$ were seen in 13 patients and values below $50000 / \mu 1$ in 3 . Mean platelet counts fluctuated during labour. The lowest values were seen immediately and 2 hours after delivery. Higher values were found 4 hours after delivery (Fig. 1). This rise, however, was not statistically significant $(P>0,01)$. The normal value for pregnancy is $210 \pm 58 \times 10^{3} / \mu \mathrm{l}$.

Fibrinogen. Fibrinogen levels on admission were studied in 52 patients. Only 14 had values between 50 and 100 $\mathrm{mg} / 100 \mathrm{ml}$ and in 13 values were below $50 \mathrm{mg} / 100 \mathrm{ml}$. Values fluctuated during the first stage of labour, but started to rise a few hours before delivery (Fig. 2). The

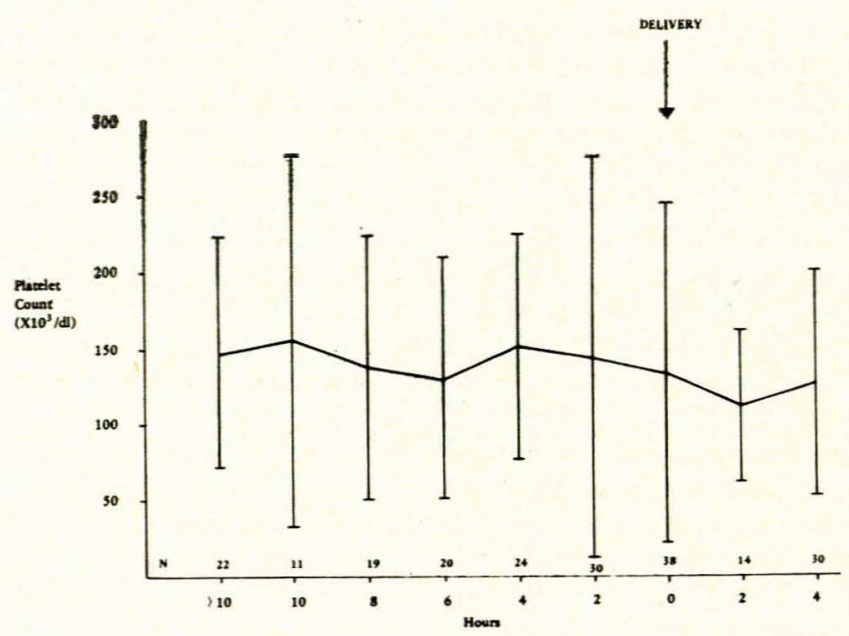

Fig. 1. Serial platelet counts during and after labour (mean and SD).

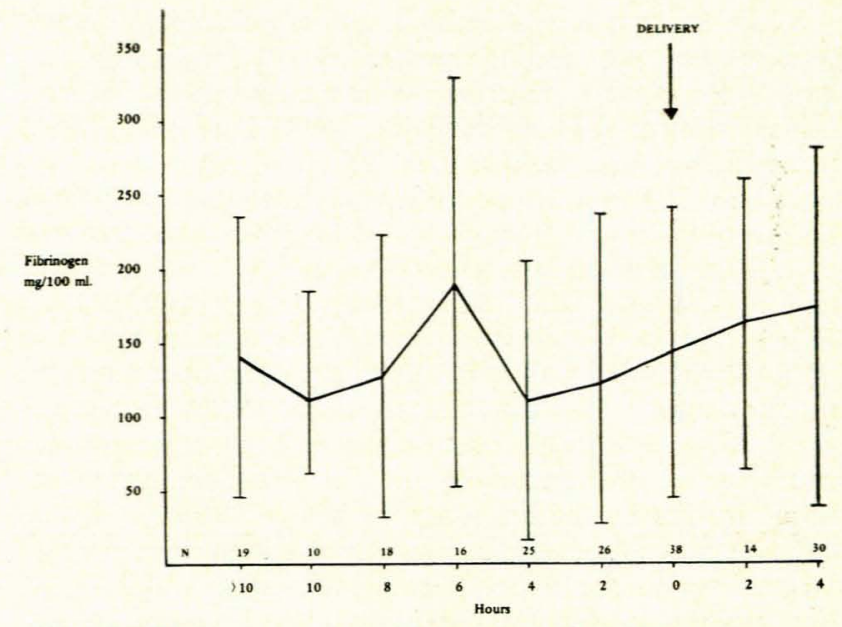

Fig. 2. Fibrinogen values during and after labour (mean and SD).

difference between the values 4 hours before and 4 hours after delivery was statistically significant $(P<0,02)$ but the difference between the values just after and 4 hours after delivery was not $(P>0,1)$. The normal value is $367 \pm$ $55 \mathrm{mg} / 100 \mathrm{ml}$. In patients in whom the initial fibrinogen values were more than $200 \mathrm{mg} / 100 \mathrm{ml}$, the mean blood loss was $726 \mathrm{ml}$ but when the initial fibrinogen values were less than $200 \mathrm{mg} / 100 \mathrm{ml}$, blood loss measured 1314 $\mathrm{ml}(P<0,05)$.

Fibrinogen degredation products. FDPs were examined in 56 patients soon after admission. Only 5 patients had values of $10 \mu \mathrm{g} / \mathrm{ml}$. Most of the patients had values exceeding $20 \mu \mathrm{g} / \mathrm{ml}$. When done serially during labour the highest values were demonstrated early on and then again just before delivery. Values subsequently started to decline (Fig. 3). The decline in the values from the 2 hours before

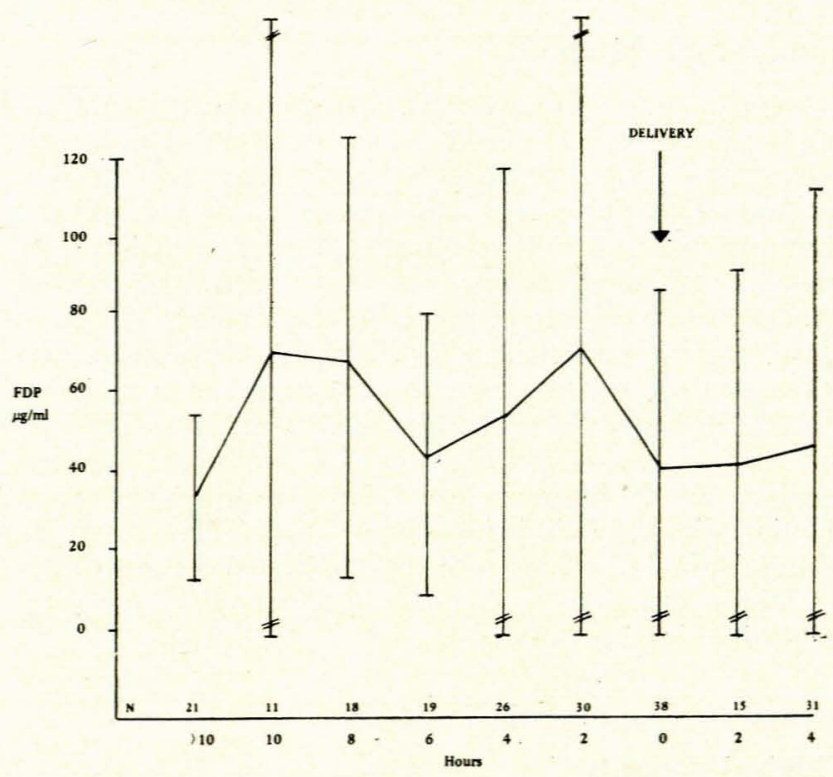

Fig. 3. Fibrinogen degradation products (FDP) during and after labour (mean and SD). 
to 4 hours after labour, was statistically significant $(P<0,1)$. In patients in whom the initial fibrinogen values were less than $50 \mathrm{mg} / 100 \mathrm{ml}$ the mean FDPs were 141 , but when the initial fibrinogen values were more than $50 \mathrm{mg} / 100 \mathrm{ml}$ the mean FDPs were $49 \mu \mathrm{g} / \mathrm{ml}(P<0,01)$. The normal value is $\leqslant 10 \mu \mathrm{g} / \mathrm{ml}$.

Partial thromboplastin time. In 52 patients the PTT was done immediately after admission. Twenty of these patients had values longer than 45 seconds. When measured serially during labour, no specific trend could be observed except for a high value before delivery. After delivery, however, values returned to normal. A significant difference $(P<0,01)$ was found when the values 2 hours before delivery were compared with values 4 hours after delivery. The normal value is $36 \pm 4,8$ seconds.

Prothrombin ratio. Initial PRs were done in 52 patients 18 of whom demonstrated abnormal ratios. During labour the mean values fluctuated, demonstrating an upward trend towards the end of the first stage. Four hours after delivery the mean PR was back to normal. These differences, however, were not significant $(P>0,1)$. The normal value is $1,01 \pm 0,03$.

Prothrombin activity. Measurements were done in 53 patients. Values lower than $70 \%$ were found in only 6 patients. Mean values during labour demonstrated a very small increase, starting from the beginning of the examination period with the highest value 2 hours after delivery. The normal value is $98 \pm 11 \%$.

Thrombin time. Tests were done in 48 patients, of whom 32 had values longer than 15 seconds. Mean values during labour demonstrated a peak in the 2-hour period just before delivery, but a normal mean value was found 4 hours after delivery (Fig. 4). The decline in the values from 2 hours before labour to 4 hours after delivery, was statistically significant $(P<0,01)$. The normal value is $11,7 \pm 0,8$ seconds.

Ethanol gelation test (test for fibrinogen monomers). Ethanol gelation tests were done in 52 patients. Tests were

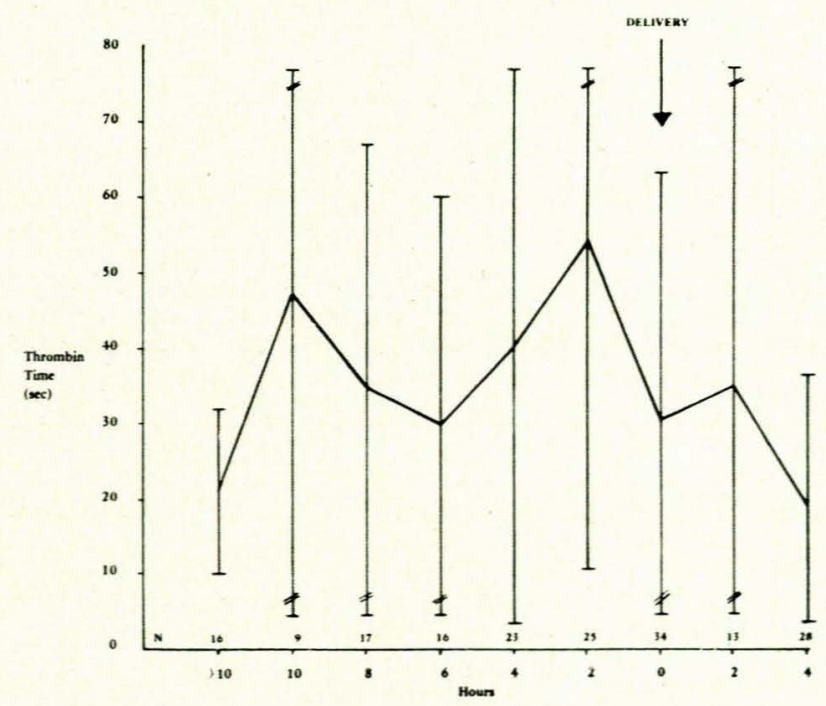

Fig. 4. Thrombin time during and after labour (mean and SD). positive on admission in 41 patients and negative in 11 . In the $8-10$ hours before labour, $90 \%$ of these tests were positive. A steady decline then occurred during labour, and 4 hours after delivery only $40 \%$ of tests were positive. In 9 patients with negative fibrin monomers, fibrinogen values exceeded $100 \mathrm{mg} / 100 \mathrm{ml}$. In 1 patient the fibrinogen value was $72 \mathrm{mg} / 100 \mathrm{ml}$, the FDP $320 \mu \mathrm{g} / \mathrm{ml}$ and the PR, PTT and TT were all severely affected. FDP values in all the other cases with negative monomers never exceeded $40 \mu \mathrm{g} /$ $\mathrm{ml}$. Only 6 patients had negative monomers in combination with a platelet count of more than $100000 / \mu \mathrm{l}$ and a fibrinogen value of more than $100 \mu \mathrm{g} / 100 \mathrm{ml}$. None of these patients had abnormal coagulation. No positive test was found in 26 normal patients.

Packed cell volume. A very small decline in the packed cell volume was noted during labour, followed by a gradual increase after delivery.

\section{DISCUSSION}

Abruptio placentae is still a cause of maternal mortality. When all cases of abruptio placentae are taken into account the maternal mortality rate varies between $0,3 \%$ and $2,8 \% .^{10-12}$ Bussamara $^{13}$ reported a mortality rate of $1,7 \%$ but it rose to $15,1 \%$ in complicated cases. In cases associated with fetal death, maternal mortality may approach $11 \% .^{14}$ Excellent results, however, could be achieved by careful patient monitoring. Pritchard ${ }^{1}$ reported no maternal deaths in 250 cases of abruptio placentae complicated by fetal death. Important causes of death are postpartum haemorrhage, shock and renal failure. All these causes are associated with severe hypovolaemia. No maternal deaths occurred in this study. Due to the severe vasoconstriction, recording of the arterial blood pressure may be misleading because normal values are maintained by the increased peripheral resistance. In 13 patients with severe abruptio placentae reported by O'Driscoll and McCarthy, ${ }^{15}$ only 6 had a systolic blood pressure lower than $100 \mathrm{mmHg}$. During this series blood pressure on admission was below $100 \mathrm{mmHg}$ in only 8 patients; on the other hand, $34 \%$ of patients had diastolic blood pressures of $90 \mathrm{mmHg}$ or more. These patients, however, had lost a considerable volume of blood as the mean volume transfused was 5,1 units. The severity of the blood loss is further indicated by the fact that the packed cell volume did not increase during labour. In spite of liberal transfusion, values increased very slowly and only after delivery. Adequate transfusion and fluid replacement, without the CVP being recorded, are difficult because of the fear of overtransfusion. ${ }^{15,16}$ Recording of the CVP could also decrease the incidence of renal failure or low puerperal haemoglobin concentrations. ${ }^{17}$

Patients with abruptio placentae could also develop extensive coagulation deficiencies caused by intravascular coagulation and secondary fibrinolysis. The end results are hypofibrinogenaemia, platelet deficiency and reduced factors V and VIII. ${ }^{18-20}$ Only 14 out of 52 patients demonstrated fibrinogen levels higher than $200 \mu \mathrm{g} / 100 \mathrm{ml}$. A platelet count exceeding $200000 / \mu \mathrm{l}$ was seen in only 13 of the 51 patients studied.

Abruptio placentae is an important condition associated 
with disseminated intravascular coagulopathy. ${ }^{21}$ Early diagnosis and treatment are essential. In our series of patients with abruptio placentae, coagulation deficiencies, as measured by PTT, PR and TT, were seen in about half the patients. In these patients the platelet count, fibrinogen level, FDP and ethanol gelation test were found to be the most reliable index of disseminated intravascular coagulopathy. However, anaemia and blood transfusion could have influenced these results. No patient had overt haemorrhage although some had features of clinical shock. Coagulation deficiency in a patient in whom abruptio placentae has caused intra-uterine death is therefore highly likely, and steps should be taken to correct these deficiencies before delivery of the fetus, especially when a caesarean section is planned. The best way of correcting the coagulation deficiency is to administer fresh blood or fresh frozen plasma as a temporary measure while waiting for compatible blood. In special circumstances, concentrated platelets could also be given. After labour, the coagulation deficiency improves and 4 hours later most of the tests are within normal limits. Although the platelet count after delivery was low, no severe complication occurred, probably owing to the contraction of the uterus and atraumatic delivery in most of the cases. It is also known that reduced FDP concentrations could improve platelet function. ${ }^{22}$

During this study blood values, measured by tests such as the PTT, PR and TT, started to improve before delivery. This indicates rising levels of coagulation factors, probably due to the administration of fresh blood and clotting factors. Rupture of the membranes with lowering of the intra-uterine pressure could also reduce the release of thromboplastin from the placenta and therefore reduce intravascular coagulation with consumption of the clotting factors.

Fibrinogen monomers also started declining before delivery. It is difficult to explain how the administration of coagulation factors could have caused this decline. It could, however, be explained by reduced intravascular coagulation. The latter is caused by reduced release of thromboplastic substances from the placenta. Improved circulation and tissue perfusion could be another contributing factor, since it is known that hypoxia and acidosis cause intravascular coagulation. Postpartum haemorrhage is difficult to measure in patients with severe abruptio placentae because delivery of the placenta is immediately followed by the retroplacental clots and blood. This blood could have accumulated in the uterus before delivery or it could have been due to an atonic uterus. When the haemorrhage persists after delivery, it is more likely to be caused by an atonic uterus. In most of the patients, although the immediate postpartum blood loss was extensive, the uterus contracted well and an atonic uterus was seen in only 3 patients. This is much lower than the $27 \%$ in patients with a coagulation deficiency as reported by Basu. ${ }^{2}$ High
FDP levels probably did not play a role in 2 of our patients, as the values were 40 and $8 \mu \mathrm{g} / \mathrm{ml}$. FDP was not measured in the third patient. Brame et $a l^{23}$ found the average volume of blood given to patients with severe abruptio placentae to be $2650 \mathrm{ml}$. Renal complications such as anuria or raised blood urea were seen in only 3 patients, and in 1 it was of a minor degree. This gives about the same incidence as that in the series quoted by Abdul-Karim and Chevli. ${ }^{24}$ It should, however, be kept in mind that all their cases were not complicated by intrauterine death. The reasons for the low incidence of renal problems are probably adequate fluid replacement (sometimes $2000-3000 \mathrm{ml}$ of Plasmalyte B within an hour) as well as improved intravascular coagulation.

Coagulation tests, such as the PTT or TT, which reflect the intrinsic coagulation factors, were abnormal in $38 \%$ and $67 \%$ of cases respectively. On the other hand tests such as the PR, which gives an indication of the extrinsic system, were abnormal in only $35 \%$ of cases. Factors of the intrinsic system could therefore be depleted more extensively than that of the extrinsic system. Fibrinogen, platelet count and monomers were estimated to screen for coagulation defects in patients with severe abruptio placentae. When tests for monomers were negative and when fibrinogen values exceeded $100 \mathrm{mg} / 100 \mathrm{ml}$ and platelet counts $100000 / \mu \mathrm{l}$, coagulation defects were unlikely.

Maternal morbidity and mortality could be reduced in patients with severe abruptio placentae, mainly by adequate fluid and blood administration and delivery of the fetus. The cause of this condition and its prevention, however, are still obscure.

\section{REFERENCES}

1. Pritchard, J. (1973): Clin. Haematol., 2, 563.

2. Basu, K. H. (1969): J. Obstet. Gynaec. Brit. Cwlth, 76, 481 3. Dacie, J. V. and Lewis, S. M. (1975): Practical Haematology. London: J. \& A

Poller, L. (1975): Thrombos. Diathes. haemorrh. (Stuttg.), 33, 157.,

5. Poller, L. (1975): Thrombos. Diathes.

5. Owren, P. A. (1959): Lancet, 2, 754 . chim. Acta, 8, 418 .

7. Elkman, L., Carvalho, A. and Colman, R. W. (1973): New Engl. J. Med., 288, 633 .

8. Thompson, J. M. (1970): A Practical Guide to Blood Coagulation and Haemostasis, p. 176. London: J. \& A. Churchill.

9. Godal, H. C., Abilgaard, U. and Kierulf, P. (1971): Scand. J. Haem., suppl. 13, p. 189.

10. Blair, R. C. (1973): J. Obstet. Gynaec. Brit. Cwlth, 80, 242.

11. Lunan, C. B. (1973): Ibid., 80, 120.

12. Porter, J. (1960): Obstet. and Gynec., 15, 690.

13. Bussamara, N. (1969): Int. J. Surg., 52, 474.

14. Hodgkinson, C. P. and Neufeld, J. (1960): Clin. Obstet. Gynec., 3, 585 .

15. O'Driscoll, K. and McCarthy, J. R. (1966): J. Obstet. Gynaec. Brit. Cwith, 73, 923.

16. Muldoon, M. J. (1969): Ibid., 76, 225.

17. De Valera, E. (1968): Amer. J. Obstet. Gynec., 100, 599.

18. Bonnar, J., McNicol, G. P. and Douglas, A. S. (1969): J. Obstet. Gynaec. Brit. Cwlth, 76, 799.

19. Kleiner, G. J. and Greston, W. M. (1976): J. Reprod. Med., 17, 309.

20. Czapee, E. E. (1973): Int. Anesthesiol. Clin., 11, 175.

21. Sharp, A. A. (1977): Brit. med. Bull., 33, 265.

22. Coopland, A. T. and Livingstone, R. A. (1970): Canad. med. Ass. J., 103, 377

23. Brame, R. G., Harbert, G. M., McGaughey, H. S. et al. (1968) Obstet. and Gynec., 31, 224.

24. Abdnl-Karim, R. W. and Chevli, R. N. (1976): Clin. Obstet. Gynec., $19,533$. 